\title{
EVOLUTION OF VERTICAL FARMS AND THE DEVELOPMENT OF A SIMULATION METHODOLOGY
}

\author{
DIANA WALDRON \\ Welsh School of Architecture (WSA), Cardiff University, UK
}

\begin{abstract}
Agricultural practices are at a significant cross roads: continuous population growth, increasing evidence of food shortage and reduced land availability are just a few of the problems highlighting the need to improve existing agricultural methods. Moreover, recurrent emerging episodes of catastrophic natural phenomena occurring across the world, such as global warming, increased natural disasters and depletion of natural resources are pushing the bar even higher, in terms of the urgent need to find viable solutions to tackle food security. The research community is under pressure to find solutions towards the above issues in tandem with the protection of the natural environment and the need to improve quality of life. In parallel, the architectural challenges are outlined by the same realities, because cities will continue to grow and it is imperative to find solutions to minimise the impact of urban development on the planet. Two key areas have been identified in this research, they are considered to have the potential to simultaneously help to mitigate the problems mentioned above: 1) Improved design of buildings and cities to encourage urban biodiversity, i.e. better urban design and architectural practices. 2) Enhanced methods to produce, store and distribute food, i.e. improved rural and urban agriculture: produce, storage and distribution. Scrutiny into these topics lead this investigation into vertical farming and the exploration on how it can be improved. A simulation methodology is under development, aiming to reproduce the potential capabilities of vertical farms, exploring their wider viability and their integration into existing and new buildings. This paper follows the development of this methodology, its current capabilities and the future directions of this ongoing investigation.
\end{abstract}

Keywords: vertical farming, computer simulation, plants and architecture, sustainable urban agriculture.

\section{INTRODUCTION}

Nature has inspired humans to find solutions to a number of problems [1], this is also known as biomimicry or biomimetic. There are several examples within architecture where the integration of plants provided the best solutions to specific problems [2]-[5]. This synergy between plants and buildings already has a momentum that should be encouraged, better yet at a large-scale. Nature inspired solutions offer a significant source of knowledge-transfer opportunities, as other research has already demonstrated [3], [6]. Indeed, it has been seen that such interesting concept of biomimicry has been exploited to some extent in the built environment, nevertheless, examples of it at a large scale are a lot scarcer.

Cities have been compared to complex living organisms that can grow organically according to the needs of its inhabitants (biomimicry principle).

\section{"Cities should learn to behave as ecosystems rather than parasites."}

(Despommier [7])

By replicating the behaviour of living organisms and learning from the principles of biology, cities' mechanisms can be redirected towards finding the most efficient solutions [2], moving from the typical linear economy and create a paradigm shift into a circular economy, as well as becoming creative with waste streams, for instance, making it into a useful process (i.e. anaerobic digestion to obtain energy). Building up from this idea, Samangooei et al. [8] suggest that "cultivating food on buildings and how we can do this is 
key to making every element of a city multifunctional and contribute to its sustainability and habitability" [8].

"Of all the resources needed to sustain a city, none is more important than food"

(Lim and Liu [9])

The concepts above are illustrating how cities already have some of the tools to behave as "ecosystems". However, throughout the centuries cities became the epicentres of consumption, where most of the Earth's resources are used and wasted. As a result, the "behaviour" of cities could be more closely comparable to parasites rather than ecosystems [7]. However, with a better understanding of urban development and the integration of plants in the built environment, a number of strategies can be followed to improve the current situation. This research aims to merge "plants and architectural" knowledge [10] in order to find viable solutions to the problems mentioned above.

Thorough studies and experiments in the area of urban greening and urban farming have taken place around the world, including the concept of vertical farming [11]-[14]. However, despite all the advances and research undertaken evaluating the integration of green elements and farming activities in cities, less sustainable practices are predominant specially in the area of agriculture, it is evident that more research is required [15]-[18].

Besides significant issues such as food security, air pollution, water preservation and more [12], [19], there is also an important driver to continue research in the area of urban plants and food production: The preservation of plant species themselves and their biodiversity. This is interestingly expressed by Lewis-Jones [20], he explores the common marginalisation of plants throughout the development of the human race. In his book chapter, he reflects on how plants are currently described as "a green background to human activity" [20]. According to him, the increased in urbanisation and reduced direct contact with plants is leading the general public towards "plant blindness" [20]. In turn, this has led to the decrease of biocultural diversity and the drastic changes of land use has increased the number of plants threaten with extinction. Increase in urban farming activities can potentially improve the knowledge of plants of the general public.

\section{VERTICAL FARMS}

As highlighted in the introduction section, there is an urgent need to make cities more sustainable and in general greener [9], [21]. Even though "sustainability principles are increasingly used to guide neighbourhood development" [22], urban sprawl is creating a number of negative issues in cities, such as air and water pollution, increased noise levels, reduced vegetation and consequently increased Urban Heat Island effect (UHI) and global warming [12], [19]. However, cities can also hold a key for the solutions to these problems, "cities as solutions" [9]. There has been a significant amount of research in the area of greening cities, evidence has been found supporting that such greenery elements and systems have a significant effect on mitigating UHI [12], [23] as well as all the other problems previously stated [19], [24]. Examples such as green wall and green roofs have been relatively well investigated around the world [11], [12], [24]-[26]. "Applying vertical greenery systems not only reduce temperature, but also have many economic, environmental and social benefits" [19]. The research community has unveiled large amounts of data on how these systems work and perform under different conditions [11], [12], [27]. For instance, interesting advancement has been done on the thermal properties of green walls/roofs in order to insulate buildings more effectively [24]. Nevertheless, published evidence shows that significantly less research and figures have been disseminated in the area of vertical farming. 


\subsection{The concepts of vertical farms and vertical farming}

Aiming to establish some clarity on the basic concepts, one might think that it would be a straight forward process to establish the definition of "vertical farms". However, even in the published world it is a lot more complex than it seems, this is due to the non-standardised manner by which vertical farming is documented as. Different publications, industries and other stakeholder in general have their own definitions on vertical farms. Therefore, this investigation will start from the basics, effectively building the foundations of this topic by stating the important difference between these two concepts:

- Vertical farm: As a noun.

- Vertical farming: As an activity.

Across the literature these two terms seem to be merged, as if the noun was the same as the activity. If the vertical farming community does not have a clear understanding of the very basics, or the foundation, of these concepts, then it is unsurprising that there is a lack of cohesiveness across the overall knowledge and understanding of vertical farms. Therefore this paper aims to achieve some clarity on the most appropriate context for both terms, in order to achieve consistency. By establishing congruency at the foundation of this research, this project aims to structure a replicable methodology to analyse vertical farms in order to make them more efficient, sustainable and also available to more people.

Despommier himself (commonly referred to as "the father of modern vertical farms" [28]) sometimes uses the acronym VF to denote vertical farms (or VFs) - the noun [29], [30]. However, Despommier published an interesting section for the for Thomson and Kaplan's Encyclopaedia for Food and Agriculture [30], where he describes VFs to be a form of Controlled Environment Agriculture (CEA) - which really is an activity. Building on this interesting passage published in the Encyclopaedia [30], Despommier describes how by the year 2010, when he published his book on vertical farms, there were no real cases of them. After his publication [29], a number of vertical farms became a reality across the world [30]. In the above statement about vertical farms, Despommier also talks about the case of a "plant factory", without providing clarification on this different concept (more on this topic will be discussed later in this paper).

Going back to the discussion about the use of the acronym: VF, Kalantari et al. [31] begin their article referencing Despommier's work, however they use the acronym VF for the activity (i.e. vertical farming), not the noun (i.e. vertical farms). In their publication, they present vertical farming (VF) as the "answer" to solve issues related to food production challenges due to growing population, earth erosion, etc. [31]. Similarly, in their following paper Kalantari et al. [32] define the "vertical farming (VF) initiative [...] as a new method of modern agriculture [...] the practice of producing food in multi storey building or tower in controlled environment conditions". Furthermore, Banerjee and Adenaeuer [14] refer to "vertical farming (VF) [as a] system of commercial farming whereby plants, animals, fungi and other life forms are cultivated" [14].

Thus, in the continuous effort to bring cohesiveness into this topic, this research will establish the use of the acronym VF for the activity, not for the noun. Henceforth, the activity of practicing VERTICAL FARMING will be referred to as VF.

Moving into the basic definitions of the concept of VF, it should be highlighted that a number of authors provide their own concepts on this matter, not always coinciding. For instance Benke and Tomkins [33], Despommier [34], Kalantari et al. [32], Al-Chalabi [16] and Fischetti [28] claim that VF is a "model", or an "initiative", where crops are grown in 
high-rise, multi-storeys buildings. Some of these authors go even further to specify that this agricultural practice is only an urban farming method [16], [28]. However, there is evidence that VF does not necessarily take place in high-rise buildings, nor exclusive in urban areas. Frediani [35] published his work and research on the development of the first vertical farm in the UK. This was located at Paignton Zoo. They chose VF as their agricultural method to produce lettuces (and other green leaves) destined to feed the zoo animals. This particular example was not based in a high-rise building and it is located in a rather rural context.

Despite of the low number of publications in the area of vertical farms, the practice of VF overlaps significantly with some other indoor food production practices. By gathering relevant data from such practices, this can help to enrich our knowledge on VF. Some of the main terms found in the literature are briefly described below. The diagram in Fig. 1 aims to illustrate a relationship between the various relevant concepts.

Understandably, Vertical agriculture is a common term used to describe VF [36], yet a more sophisticated concept that constantly overlaps with VF is Controlled Environment Agriculture (CEA) [30], [37]. The latter terms is highly reliant on modern technology, which leads the discussion into assuming that in some cases, VF would also share this characteristic. Nevertheless, CEA is not necessarily a synonym of VF. Furthermore, a variety of other indoor agricultural concepts creep deeper into the concept of VF, such as High Density Vertical Growing (HDVG) [31], [38], which "can be considered a form of Controlled Environment Agriculture (CEA) that aims to allow people to grow food where they live, using fewer resources to produce a higher output" [35]. Frediani describes these concepts as sustainable urban agriculture. In the latter reference, Frediani merges the three terms: VF, HDVG and CEA, adding a sort of complexity to the already incongruent field of vertical farms. Other publications referring to a similar type of agricultural practice describe the wellknown Plant Factories (PF) [39]. Although vertical farms and PF are not the same, they are not mutually exclusive either, some PF can be classified as vertical farms (in most cases), but

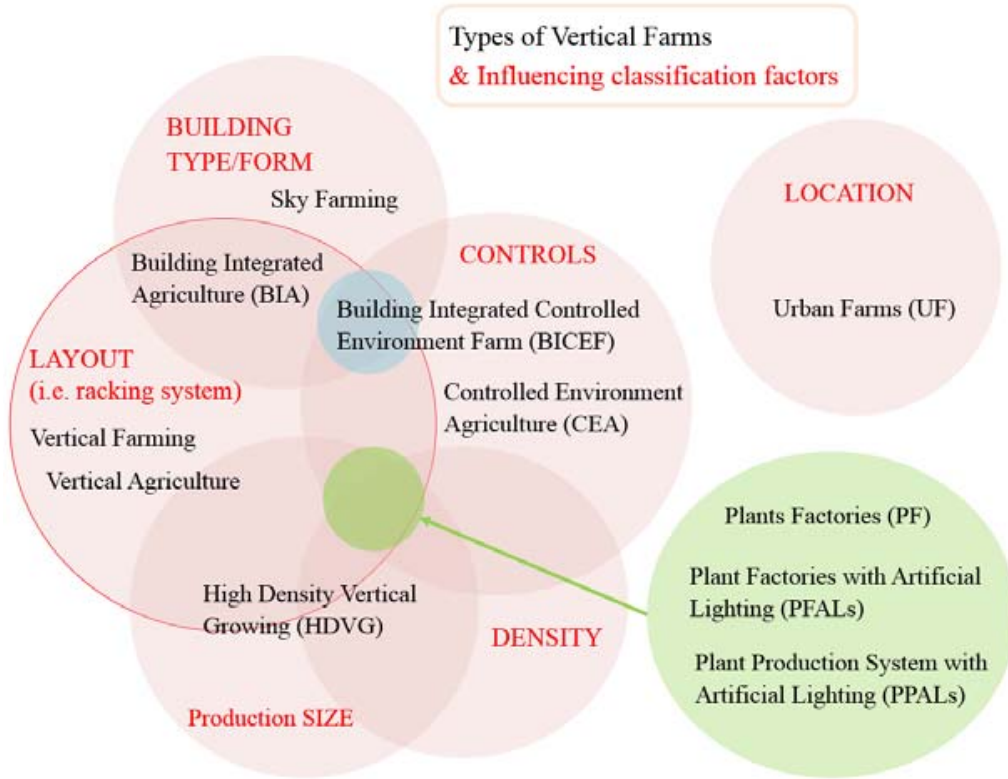

Figure 1: VF related concepts. 
not all vertical farms can be regarded as PF. On a similar stream to PF, there are two more similar published definitions: Plant Factories with Artificial Lighting (PFALs) [40] and Plant Production System with Artificial Lighting (PPALs) [41]. Based on most published information regarding PF and the related PFALs and PPALs, it becomes evident that they are agricultural practices closely linked to high density production of food. Moving into the interaction between buildings and plants, this investigation also looked into published work in the area of Building Integrated Agriculture (BIA) [37]. Similarly, BIA along with CEA overlap with yet another research term: Building Integrated Controlled Environment Farm (BICEF) [37]. Another, less common term is Sky Farming, which aims to describe agricultural practices taking place in high-rise buildings [31]. This paper attempts to "untangle" all these concepts, which are so closely intertwined, see Fig. 1.

All of the information found in these areas have a great potential to enrich the development of vertical farms, therefore making them more efficient, sustainable and replicable. Focusing on the potential for this particular research project, these concepts can help to design a sort of clustering analysis for different classifications of vertical farms. This could result in further automatization of the simulation and ease to replicate the methodology outlined in this paper.

Summarising the data gathered in the research across all of these related concepts, it could be argued that there are six main characteristics that influence the different classifications of these types of indoor farming (Fig. 1 also shows these characteristics represented by the orange circles):

- Size.

- Density.

- Controls.

- Layout.

- Building type/form.

- Location.

\subsection{Simulations of vertical farms}

The last couple of years witnessed a great increase in the number of academic research work published in the area of urban agriculture, particularly in VF [31], [38], [41], [42]. However, almost all the publications on VF make the consensus remark that further research is needed. The findings from this investigation also support the previous statement, particularly in the area of simulation. There have been some attempts to tackle these issues from a number of angles. For instance, some research projects focused on the behaviour of plants, discussing the integration of a mathematical model based on the Penman-Monteith equation for the vertical farm's calculations [43], [44]. Some publications highlighted the importance of analysing and calculating the "energetic behaviour" of crops in order to achieve better vertical farming produce [37], [44]. Thus, this is an area that is worth exploring, as part of a further integration for the methodology presented in this paper.

Referring to the potential of knowledge-transfer, a recent publication explored the concept of learning from greenhouses modelling to attempt VF simulation [45]. The researchers provide evidence on how the knowledge and skills on managing and modelling greenhouses are valuable sources of information towards aiming to simulate vertical farms [45]. Graamans et al. [45] attempted to overcome the issue of the lack of suitable software to simulate vertical farms by using two separate software tools: KASPRO, which is a common software used to monitor and simulate the behaviour of greenhouses, and DesignBuilder as the software used to attempt to recreate the influence of the host building. In their study [45], a number of 
limitations were evident and the case study seemed unrealistic, making it difficult (if not impossible) to replicate by a third party.

Further relevant research have been published in the area of test-cells development [46][48]. Particularly, the work of Tsitsimpelis et al. [48] follows the exploration of a mechanical "conveyor-irrigation system for the mechanical movement of plants" in a vertical farm. They have followed this line of research based on the premise that the uneven air and light distribution across the different levels of a vertical farm results in the loss of quality of some of the plants' growth. They show how "the mechanical movement of the trays [...] helped to minimise the impact of temperature and humidity variation across the different trays" [48]. The latter publication also reiterates the need to further explore and improve the concept of $\mathrm{VF}$, under the overarching argument of the "optimisation of the food system, in order to deal with forthcoming changes in population and climate" [48].

\section{SIMULATION METHODOLOGY}

To develop the simulation of a vertical farm prototype for this research project, a number of different software tools have been explored and trialled. There are some computer programmes that currently assist vertical farms pioneers and entrepreneurs, however they are still highly undocumented particularly in the research communities, due to the mainly commercial nature of such agricultural practice. Software tools such as Enviment, DesignBuilder, EnergyPlus, amongst others, have been investigated during the literature review stage of this project in order to understand their potential in this area. However, there is no evidence that one specific software can be used to predict the performance of vertical farms [39], [49]. Some attempts have been made to use separate computer programmes to simulate certain parts of the process required for vertical farming, as described in the previous section [45]. However, none of these attempts had a building integrated focused, nor renewable energy potential to make it self-sustainable.

HTB2 (Heat Transfer in Buildings-2) [12], [50] is an in-house developed software tool, originally built to recreate the thermal behaviour of buildings, based on mathematical models and the laws of physics to calculate their internal temperature, predict energy consumption, humidity, amongst various other parameters. This research project has been exploring the capabilities of this software tool to recreate the behaviour of vertical farms. Consequently helping to create a methodology to predict and share data and results with a wider audience in order to allow comparable and sharable information. The flexibility and compartmentalised nature of HTB2 has the potential to fill a number of gaps found in the area of VF simulations.

The methodology suggested in this research follows four main stages (see Fig. 2 for more details):

Stage 1: THE BUILDING. Here is where basic building information is established.

Stage 2: SERVICES. This stage stores detailed information regarding the services required to run the vertical farm successfully, to encourage the crops to thrive.

Stage 3: DIARY. This stage refers to the "diary files", i.e. the schedules relevant to the effective operation of the vertical farm. For instance, the simulation process requires information regarding the type of crops and the approximate number of plants.

Stage 4: WEATHER DATA. This part of the methodology stores all the climatic information needed for the simulation period (own data files can be uploaded, otherwise this process allows to use weather data files from EnergyPlus [51]. 
VERTICAL FARM SIMULATION

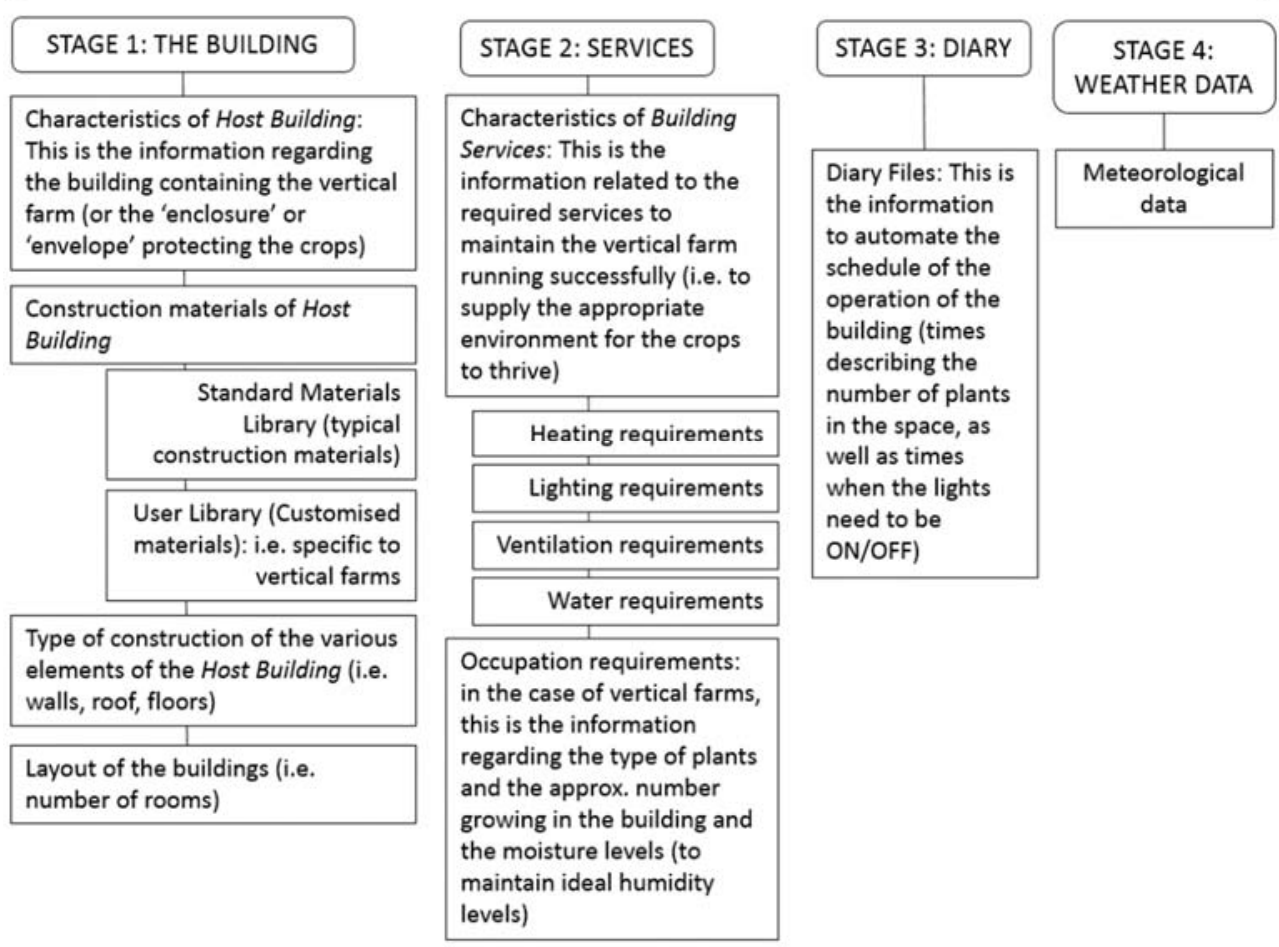

Figure 2: Simulation methodology structure.

By following the stages described in the diagram above (Fig. 2), a comprehensive analysis can be achieved to understand (and effectively simulate) the behaviour of vertical farms. The focus of this simulation is from the thermal performance of its host building and its interaction with plants. This methodology aims to assist with the prediction of the performance of a vertical plant during its planning stage, much like an early stage design tool, even before it is built, in order to reduce risks.

\section{DISCUSSION AND RESULTS}

This methodology is currently under development. The virtual base case study is helping to tailor the software tool (HTB2) to simulate the scenario of a vertical farm. Therefore, some initial figures have been obtained as a result of this virtual base case study. However, since this process is still at its trial and development stage, this final figures are not considered to be reliable yet. Nevertheless, current results are showing a satisfactory and active simulation process with significant potential, but still requires some de-bugging and further iterations in order to obtain reliable data. As a further stage of this project, the simulated data is to be compared to real-life cases of vertical farms.

The images and table (Fig. 3 and Table 1) show a small sample of the simulation process and results. The full methodology and outcomes are expected to be published in subsequent publications. Fig. 3 shows snapshots of the simplest virtual base case study created for the development stage. 

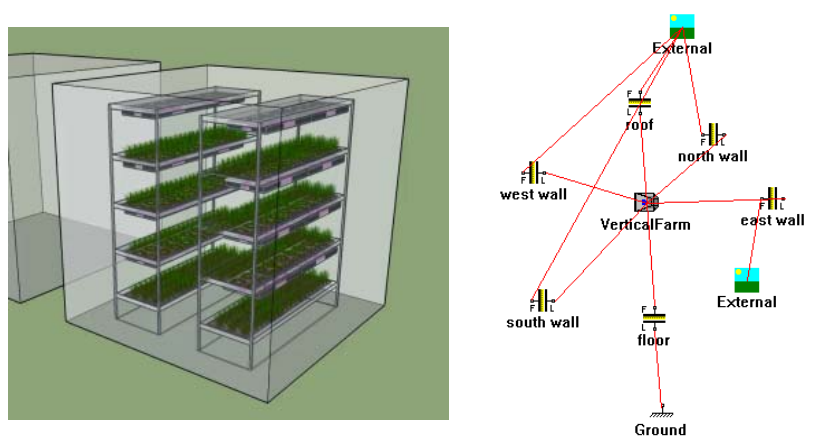

Figure 3: Graphic representation of the same virtual base case study presented in two different software. (a) SketchUp; and (b) HTB2.

Fig. 3(a) is the representation of the case study in a simple visual form using SketchUp [52]; Fig. 3(b) is the schematic representation of the same case study, using the simulation software HTB2 [50].

Table 1 provides some useful data in terms of vertical farming simulation. The table shows average monthly values over a whole year of the simulation. This is a small sample of the data, HTB2 can provide this data in more detail, i.e. hourly results or even more refined timelapses. Information such as comparative data between the external and the internal air temperature and relative humidity, provide valuable information to analyse, for example, the impact of the local weather on the stability (and potential efficiency) of the vertical farm. Further outputs are obtained from this simulation process, data such as radiant temperature and heater output provide information about the performance of the (mechanical) systems of the farm.

Furthermore, Fig. 4 shows two sample graphs where the external and internal relative humidity $(\mathrm{RH})$ monthly values are compared through the whole year, also showing how the internal RH is affected by different ventilation rates. In this example, the ventilation rate has been changed for two different simulation cycles, one runs with $3 \mathrm{ACH}$ (air changes per hour) and the second cycle runs with $5 \mathrm{ACH}$ (the design of the vertical farm remains the same). The results of the internal air humidity or RH (shown in blue in the graphs in Fig. 4) indicate

Table 1: Initial figures obtained from the virtual base case study of a vertical farm, using HTB2 as the simulation software.

\begin{tabular}{|c|c|c|c|c|c|c|}
\hline Date & Air Temperature - C & Ext Air Temperature - $\mathrm{C}$ & Air Humidity - $\%$ & Ext Rel Hum - \% & Mean RadTemp - C & Heater Outpt - W \\
\hline $31 / 01 / 2017$ & 24.174 & 6.09 & 64.392 & 88.261 & 22.097 & 114.674 \\
\hline $28 / 02 / 2017$ & 24.142 & 4.92 & 62.183 & 84.629 & 21.957 & 133.108 \\
\hline $31 / 03 / 2017$ & 24.194 & 6.60 & 63.838 & 80.816 & 22.261 & 119.525 \\
\hline $30 / 04 / 2017$ & 24.239 & 8.48 & 65.592 & 79.261 & 22.598 & 106.521 \\
\hline $31 / 05 / 2017$ & 24.524 & 12.18 & 72.012 & 87.37 & 23.232 & 70.603 \\
\hline $30 / 06 / 2017$ & 24.702 & 13.97 & 71.178 & 82.015 & 23.588 & 52.835 \\
\hline $31 / 07 / 2017$ & 25.429 & 16.06 & 69.786 & 77.45 & 24.432 & 30.101 \\
\hline $31 / 08 / 2017$ & 25.36 & 16.13 & 70.576 & 78.731 & 24.366 & 31.947 \\
\hline $30 / 09 / 2017$ & 24.522 & 13.86 & 69.813 & 77.336 & 23.345 & 56.574 \\
\hline $31 / 10 / 2017$ & 24.259 & 11.18 & 71.046 & 86.606 & 22.725 & 76.723 \\
\hline $30 / 11 / 2017$ & 24.209 & 8.56 & 67.688 & 86.017 & 22.394 & 99.275 \\
\hline $31 / 12 / 2017$ & 24.179 & 6.75 & 65.762 & 89.691 & 22.147 & 112.716 \\
\hline
\end{tabular}




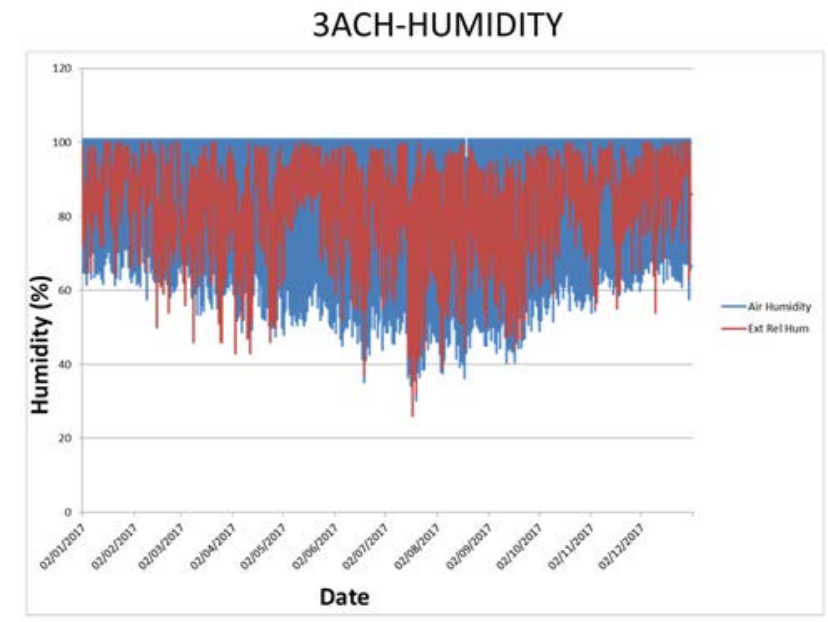

\section{ACH-HUMIDITY}

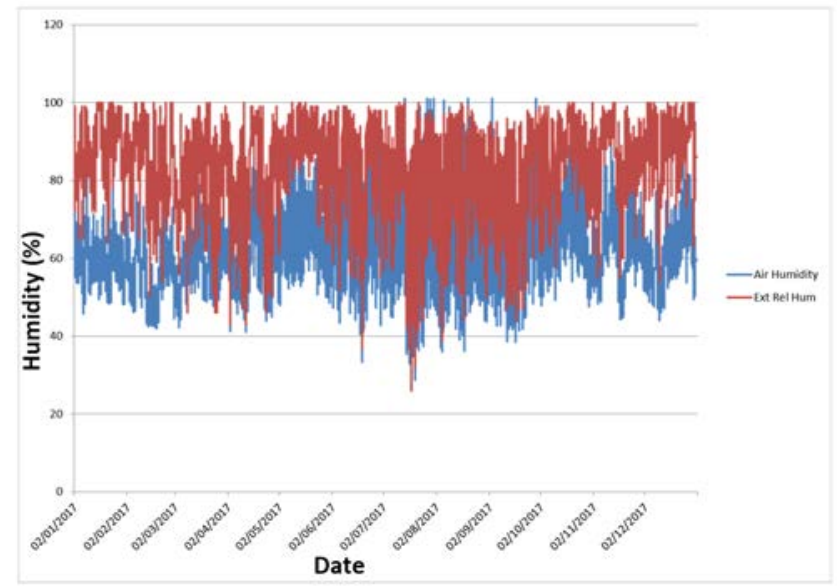

Figure 4: Comparative study of results, showing changes of relative humidity base on two different air changes per hour $(\mathrm{ACH})$.

a considerable change of the results by altering the ventilation rate. Similarly, various significant parameters can be changed and simulated to create more comparisons and optimise the design of the vertical farm. Obtaining these initial results have been a significant milestone in this research process, since it can be established that this software tool (HTB2) can indeed be used for simulations of vertical farms, its accuracy is yet to be determined. The next stage of this investigation is to finish this methodology and thereafter to validate it.

One of the main objectives of this work is to fill, to some extent, the knowledge gap in the area of VF simulation, since the research community lacks a common ground exploration tool to help investigating vertical farms. Furthermore, it is worth stating that this simulation methodology has also been developed in order to demystify the integration of vertical farms in buildings, since one of the largest obstacles of VF is the apparent requirement of "highexpertise and knowledge". This tool can potentially help to demonstrate that any 
building/structure could be used to develop a vertical farm, i.e. VF does not have to take place exclusively in lab-like environments. If the right characteristics are created, almost any building could be adequate to design a vertical farm.

\section{ACKNOWLEDGEMENTS}

The Author acknowledges the financial support provided by the Welsh Government and Higher Education Funding Council for Wales through the Sêr Cymru National Research Network for Low Carbon, Energy and Environment. Sincere thanks to the funding bodies mentioned above, as well as to Cardiff University and supportive supervisors, Prof Phil Jones and Dr Yangang Xing. Last but not least, thanks for all the encouragement received from all the invaluable members of the NRN-LCEE, in particular from Plants and Architecture cluster.

\section{REFERENCES}

[1] Lurie-Luke, E., Product and technology innovation: What can biomimicry inspire? Biotechnol Adv., 32(8), pp. 1494-4505, 2014.

[2] Pawlyn, M., Biomimicry in Architecture, RIBA Publishing: London, 2011.

[3] El-Zeiny, R.M.A., Biomimicry as a problem solving methodology in interior architecture. Procedia - Soc Behav Sci., 50, pp. 502-512, 2012.

[4] Bingham-Hall, P., Garden City Mega City Rethinking Cities for the Age of Global Warming, Pesaro Publishing, 2016.

[5] Rao, R., Biomimicry in architecture. Int. J. Adv. Res. Civil, Structural, Environmental Infrastruct. Eng. Dev., pp. 101-107, 2014.

[6] Breuste, J., Qureshi, S. \& Li, J., Scaling down the ecosystem services at local level for urban parks of three megacities. Hercynia NF, 46, 1-20, 2013.

[7] Despommier, D., TED Talk x Warwick, 2013.

[8] Samangooei, M., Sassi, P. \& Lack, A., Soil-less systems vs. soil-based systems for cultivating edible plants on buildings in relation to the contribution towards sustainable cities. Futur. Food J. Food, Agric. Soc., 4(2), pp. 24-39, 2016.

[9] Lim, C. \& Liu, E., Smartcities + Eco-warriors, Routledge, 2010.

[10] NRN-LCEE, Plants \& Architecture. http://nrn-lcee.ac.uk/plants-architecture/ index.php.en. Accessed on: 20 Aug. 2018.

[11] Koyama, T., Yoshinaga, M., Hayashi, H., Maeda, K.I. \& Yamauchi, A., Identification of key plant traits contributing to the cooling effects ofgreen façades using freestanding walls. Build Environ., 66, pp. 96-103, 2013.

[12] Alexandri, E. \& Jones, P., Temperature decreases in an urban canyon due to green walls and green roofs in diverse climates. Build Environ., 43(4), pp. 480-493, 2008.

[13] Pérez, G., Coma, J., Martorell, I. \& Cabeza, L.F., Vertical Greenery Systems (VGS) for energy saving in buildings: A review. Renew. Sustain. Energy Rev., 39, pp. 139$165,2014$.

[14] Banerjee, C. \& Adenaeuer, L., Up, up and away! The economics of vertical farming. J. Agric. Stud., 2(1), p. 40, 2014.

[15] Breuste, J., Qureshi, S. \& Li, J., Applied urban ecology for sustainable urban environment. Urban Ecosyst., 16(4), pp. 675-680, 2013.

[16] Al-Chalabi, M., Vertical farming: Skyscraper sustainability? Sustain. Cities Soc., 18, pp. 74-77, 2015.

[17] Davis, M.M. \& Hirmer, S., The potential for vertical gardens as evaporative coolers: An adaptation of the "Penman Monteith Equation". Build Environ., 92, pp. 135-141, 2015. DOI: http://dx.doi.org/10.1016/j.buildenv.2015.03.033. 
[18] Campus, J., Building, E. \& Kozai, T., Role of Plant Factory with Artificial Light (PFAL) in Urban Horticulture and Next Generation Lifestyle, 2014.

[19] Safikhani, T., Abdullah, A.M., Ossen, D.R. \& Baharvand, M., A review of energy characteristic of vertical greenery systems. Renew. Sustain. Energy Rev., 40, pp. 450$462,2014$.

[20] Lewis-Jones, K.E., People and plants: World-making with plants. Environ. Soc. Adv. Res., 7(1), pp. 1-7, 2016.

[21] Howard, E., Garden Cities of To-Morrow, MIT Press, 1965.

[22] Sharifi, A., From garden city to eco-urbanism: The quest for sustainable neighborhood development. Sustain. Cities Soc., 20, pp. 1-16 2016. DOI: http://dx.doi.org/10.1016/ j.scs.2015.09.002.

[23] Cheng, X., Wei, B., Chen, G., Li, J. \& Song, C., Influence of park size and its surrounding urban landscape patterns on the park cooling effect. J. Urban Plan. Dev., 141(3), A4014002, 2015. DOI: http://ascelibrary.org/doi/10.1061/\%28ASCE\%29UP. 1943-5444.0000256.

[24] Sun, T., Bou-Zeid, E. \& Ni, G.H., To irrigate or not to irrigate: Analysis of green roof performance via a vertically-resolved hygrothermal model. Build Environ., 73, pp. 127-137, 2014. DOI: http://dx.doi.org/10.1016/j.buildenv.2013.12.004.

[25] Silva, C.M., Flores-Colen, I. \& Coelho, A., Green roofs in Mediterranean areas: Survey and maintenance planning. Build Environ., 94, pp. 131-143, 2015. http://linkinghub.elsevier.com/retrieve/pii/S0360132315300780.

[26] Solcerova, A., van de Ven, F., Wang, M., Rijsdijk, M. \& van de Giesen, N., Do green roofs cool the air? Build Environ., 111, pp. 249-255, 2017. DOI: http://dx.doi.org/10.1016/j.buildenv.2016.10.021.

[27] Brown, C. \& Lundholm, J., Microclimate and substrate depth influence green roof plant community dynamics. Landsc. Urban Plan., 143, pp. 134-142, 2015. DOI: http://dx.doi.org/10.1016/j.landurbplan.2015.07.009.

[28] Fischetti, M., Growing vertical: Skyscraper farming. Sci. Am., pp. 74-79, 2008.

[29] Despommier, D., The Vertical Farm, Picador: USA, 2010.

[30] Despommier, D., Vertical farms in horticulture. Encyclopedia of Food and Agricultural Ethics, eds P.B. Thompson \& D.M. Kaplan, Springer: Dordrecht, pp. 1791-1799, 2014. http://link.springer.com/10.1007/978-94-007-0929-4_88.

[31] Kalantari, F., Mohd Tahir, O., Mahmoudi Lahijani, A. \& Kalantari, S., A review of vertical farming technology: A guide for implementation of building integrated agriculture in cities. Adv. Eng. Forum, 24(October), pp. 76-91, 2017.

[32] Kalantari, F., Tahir, O.T., Joni, R.A. \& Aminuldin, N.A., The importance of the public acceptance theory in determining the success of the vertical farming projects. $J$. Manag. Res. Pract., 10(1), 2018.

[33] Benke, K. \& Tomkins, B., Future food-production systems: Vertical farming and controlled-environment agriculture. Sustain. Sci. Pract. Policy, 13(1), pp. 13-26, 2017. DOI: https://doi.org/10.1080/15487733.2017.1394054.

[34] Despommier, D., The rise of vertical farms. Sci. Am., pp. 80-87, 2009.

[35] Frediani, K., Sustainable food production in the modern zoo and its wider role in a time of global change. Proceedings of the UK Controlled Environment Users' Group, pp. 20-33, 2011.

[36] Torreggiani, D., Dall'Ara, E. \& Tassinari, P., The urban nature of agriculture: Bidirectional trends between city and countryside. Cities, 29(6), pp. 412-416, 2012. DOI: http://dx.doi.org/10.1016/j.cities.2011.12.006. 
[37] Benis, K., Reinhart, C. \& Ferrão, P., Building-Integrated Agriculture ( BIA ) in urban contexts : testing a simulation-based decision support workflow. 15th International Building Performance Simulation Association (IBPSA) Conference, pp. 1798-1807, San Francisco, USA, 2017.

[38] Shamshiri, R.R. et al., Advances in greenhouse automation and controlled environment agriculture: A transition to plant factories and urban agriculture. Int. J. Agric. Biol. Eng., 11(1), pp. 1-22, 2018.

[39] Kozai, T., Niu, G. \& Takagaki, M., Plant Factory An Indoor Vertical Farming System for Efficient Quality Food Production, Elsevier Academic Press, 2016.

[40] Luna-Maldonado, A.I., Vidales-Contreras, J.A. \& Rodríguez-Fuentes, H., Advances and Trends in Development of Plant Factories, 2017. www.frontiersin.org/researchtopics/3226/advances-and-trends-in-development-of-plant-factories.

[41] Kozai, T., Resource use efficiency of closed plant production system with artificial light: concept, estimation and application to plant factory. Proc. Jpn Acad. Ser. B Phys. Biol. Sci., 89(10), pp. 447-461, 2013. http://www.pubmedcentral.nih.gov/ articlerender.fcgi?artid $=3881955 \&$ tool $=$ pmcentrez\&rendertype $=$ abstract.

[42] Kalantari, F., Tahir, O.T., Joni, R.A. \& Fatemi, E., Opportunities and challenges in sustainability of vertical farming: A review. J. Landsc. Ecol., 2(2), 2017.

[43] Allen, R., Penman-Monteith equation. Encycl. Soils Environ., pp. 180-188, 2005.

[44] Graamans, L., van den Dobbelsteen, A., Meinen, E. \& Stanghellini, C., Plant factories; Crop transpiration and energy balance. Agric. Syst., 153, pp. 138-147, 2017. DOI: http://dx.doi.org/10.1016/j.agsy.2017.01.003.

[45] Graamans, L., Baeza, E., van den Dobbelsteen, A., Tsafaras, I. \& Stanghellini, C., Plant factories versus greenhouses: Comparison of resource use efficiency. Agric. Syst., 160, pp. 31-43, 2018.

[46] Tsitsimpelis, I. \& Taylor, C.J., Micro-climate control in a grow-cell: System development and overview. IFAC Proceedings Volumes, 47, pp. 4417-4422, 2014.

[47] Cattarin, G., Causone, F., Kindinis, A. \& Pagliano, L., Outdoor test cells for building envelope experimental characterisation: A literature review. Renew. Sustain. Energy Rev., 54, pp. 606-625, 2016. DOI: http://dx.doi.org/10.1016/j.rser.2015.10.012.

[48] Tsitsimpelis, I., Wolfenden, I. \& Taylor, C.J., Development of a grow-cell test facility for research into sustainable controlled-environment agriculture. Biosyst. Eng., 150, pp. 40-53, 2016.

[49] Graamans, L., Baeza, E., van den Dobbelsteen, A., Tsafaras, I. \& Stanghellini, C., Plant factories versus greenhouses: Comparison of resource use efficiency. Agric. Syst., 160, pp. 31-43, 2018.

[50] Lewis, P. \& Alexander, D., HTB2: A flexible model for dynamic building simulation. Build Environ., 25(1), pp. 7-16, 1990.

[51] EnergyPlus, EnergyPlus Weather Data. https://energyplus.net/weather.

[52] SketchUp Official Web Page. https://www.sketchup.com/. 